\title{
Editor's Note: Introducing Intervention Studies as a New Article Category
}

\author{
Daniel H. Robinson
}

Published online: 12 August 2012

(C) Springer Science+Business Media, LLC 2012

I have fond memories as a graduate student reading such journals as the Journal of Experimental Psychology: Learning, Memory, and Cognition and being excited to learn of all the wonderful research that had classroom learning implications. Unfortunately, the contributions of cognitive psychology have not permeated the educational psychology journals. Whatever the reason, I feel that we in the educational psychology community should consider these contributions to expand and enhance our understanding of learning in the classroom. Thus, it is my hope that this special issue on the contributions of cognitive psychology to educational psychology will foster deeper, more meaningful and lasting connections between the two fields. I wish to thank the authors who contributed to this special issue, Shana Carpenter, Jeff Karpicke, Elizabeth Marsh, Katherine Rawson, Doug Rohrer, and Lisa Son, for sharing their work with us. I also thank Pooja Agarwal for serving as guest editor.

I am pleased to report that the journal continues to do well. In 2011, we received 89 manuscripts - the most in my 6 years as editor. Back in 2006, we received 33. Our impact factor has stayed above 2.400 for the past 3 years. The average number of days from submission to initial decision in 2011 was 38 . This is down from 51 days in 2006. So we continue to improve on most indicators. It is with this upbeat news that I would like to introduce some changes in the article categories we welcome at Educational Psychology Review (EDPR).

Since 2006, EDPR has had the following article categories: review, reflection/comment, interview, research-into-practice, and replication. The integrative review article continues to be our bread and butter. As I have mentioned, the research-into-practice article is, unfortunately, the most misunderstood and results in the majority of my desk rejects (i.e., without additional peer review). I am granting it a merciful death - it will no longer appear. Although we have not received many replication studies, I am stubbornly keeping the category in the hopes that eventually replications will be valued in our field. Wainer (2012, pp. 358-359) recently described the function and importance of replications:

D. H. Robinson $(\square)$

School of Education, 209 Education Building, Colorado State University,

Fort Collins, CO 80523-1588, USA

e-mail: dan.robinson@colostate.edu 
The principal epistemological tenet of the paradigm for modern science is replicability and was laid out by Francis Bacon in the early seventeenth century. Replicability begins with the idea that science is not private and so claims that are made by one person must be available to be tested by others. The way in which this idea has grown over time starts with the recognition that initial investigations are almost always done on a small scale, and, hence, they exhibit the variability inherent in small studies. What this means is that there will be results reported that are epiphenomenal (e.g., false positives). But when such things appear in the scientific literature, other investigators will rush to replicate. If the attempts to replicate don't pan out, the initial result is brushed aside as the statistical anomaly it was and science moves on. Scientific tradition sets an initial acceptance criterion for much research that tolerates a fair number of false positives (typically, one time out of twenty) because:

1. It is impractical to do preliminary research on any topic that is on a large enough scale to diminish the likelihood of statistical artifacts to truly tiny levels, and

2. It is more difficult to rediscover a true result that was previously dismissed because it failed to reach some stringent level of acceptability than it would be to reject a false positive after subsequent work fails to replicate it.

This approach has meant that the scientific literature is littered with an embarrassing number of remarkable results that were later shown to be anomalous.

In educational psychology, we truly do not know if our literature is littered with anomalous findings because, in general, we do not attempt to replicate others' work. I suggest that if we would like to be taken more seriously in the scientific community, we should demonstrate the stability of potentially useful interventions through independent replication. EDPR encourages such replications.

To replace the deceased research-into-practice article, I would like to introduce a new article category: intervention studies. I realize that this goes against my first editorial policy in 2006, in which I stated that EDPR would publish almost anything except papers that report original empirical research. Let me explain my reasoning for bucking tradition.

About 10 years ago, several colleagues and I began a series of descriptive investigations that examined the types of articles published in several empirical educational psychology journals (e.g., American Educational Research Journal, Contemporary Educational Psychology, and Journal of Educational Psychology). What we found was that intervention research, in which the researcher manipulates one or more independent variables and measures the effect on one or more dependent variables, was becoming increasingly rare. The percentage of articles employing randomized experiments has dropped from $40 \%$ in 1983 to just $23 \%$ in 2010 (Hsieh et al. 2005; Reinhart et al. 2012; Robinson et al. 2007). What has replaced intervention studies is what I would call observational studies (e.g., descriptive, correlational, qualitative). Moreover, these nonintervention studies are producing recommendations for practice at increasing rates (Reinhart et al.; Robinson et al.). It seems that the en vogue way to establish causality these days is to employ sophisticated statistical modeling techniques with correlational data and then crank out recommendations for practice. Anecdotally, several of my colleagues have told me that it is becoming more difficult to publish their intervention studies. I have also experienced this as an author.

Therefore, my rationale for introducing a new article category is simply to provide an outlet for quality intervention studies that are not finding their way into educational psychology journals. I do not think this will encroach on the "turf" of existing 
empirical educational psychology journals. The data indicate that they rarely publish intervention studies. So look for new article categories and instructions for authors to appear soon.

Each year, I am sad to see editorial board members step down as a result of other commitments, but I realize such is life, and I appreciate their responsibility to step away when life becomes too busy. I would like to thank departing board members Lyn Corno, Gale Sinatra, Keith Stanovich, and Barry Zimmerman for their service. Any success the journal has had under my watch can be contributed solely to the quality of reviews that folks like these have given unselfishly. To be able to handle increasing submissions, I am welcoming the following new editorial board members: Michelle Buehl, Shana Carpenter, Catherine McBride-Chang, Andrea Flower, Hunter Gehlbach, Paul Ginns, Robin Henson, Slava Kalyuga, Mark McDaniel, Jason Osborne, Shana Shaw, and Jeroen van Merrienboer. My hope is that readers like you will continue to consider EDPR as an outlet for your best papers and as a source for the most current and cutting-edge work produced by educational psychologists.

\section{References}

Hsieh, P.-H., Hsieh, Y.-P., Chung, W.-H., Acee, T., Thomas, G. D., Kim, H.-J., et al. (2005). Is educational intervention research on the decline? Journal of Educational Psychology, 97, 523-529.

Reinhart, A. L., Haring, S. H., Levin, J. R., Patall, E. A., \& Robinson, D. H. (2012). Models of not-so-good behavior: Yet another way to squeeze causality and recommendations for practice out of correlational data. Journal of Educational Psychology (in press)

Robinson, D. H., Levin, J. R., Thomas, G. D., Pituch, K. A., \& Vaughn, S. R. (2007). The incidence of "causal" statements in teaching and learning research journals. American Educational Research Journal, $44,400-413$.

Wainer, H. W. (2012). Survival of the fittists. The American Scientist, 100, 358-361. 